\title{
Multi-Column \\ Experimental Test Bed \\ Using CaSDB MOF for Xe/Kr Separation \\ Fuel Cycle Technology
}

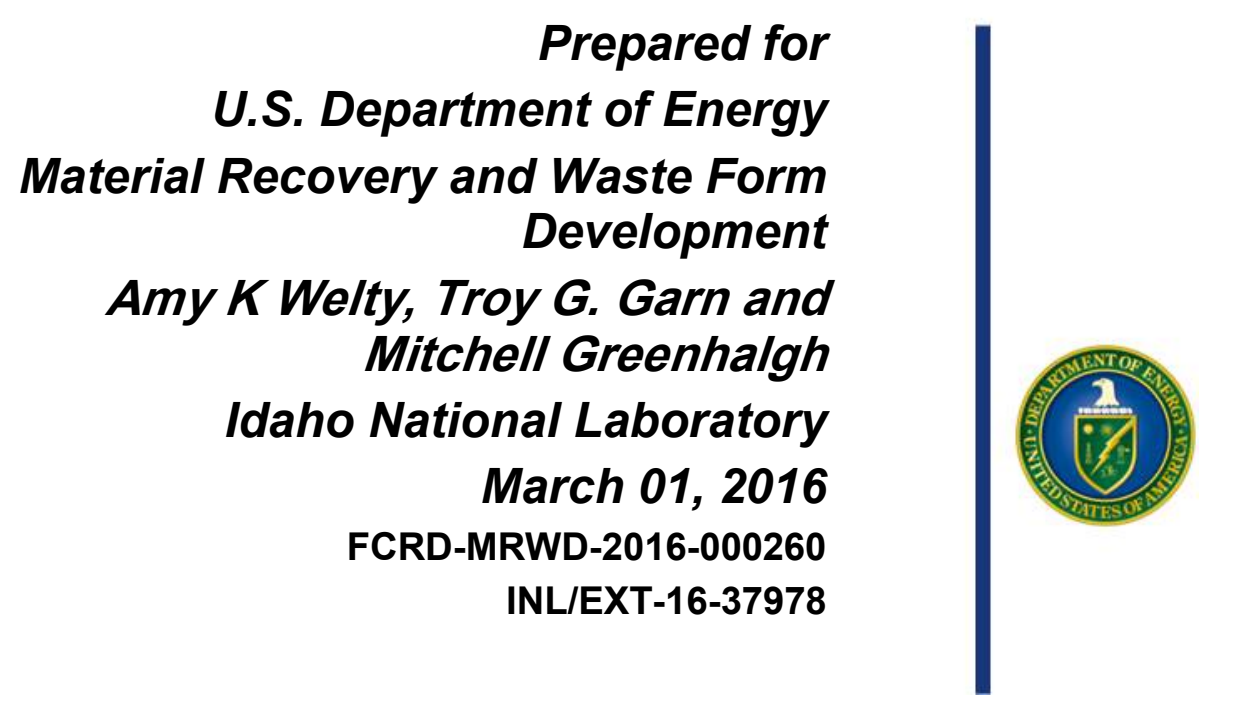





\section{DISCLAIMER}

This information was prepared as an account of work sponsored by an agency of the U.S. Government. Neither the U.S. Government nor any agency thereof, nor any of their employees, makes any warranty, expressed or implied, or assumes any legal liability or responsibility for the accuracy, completeness, or usefulness, of any information, apparatus, product, or process disclosed, or represents that its use would not infringe privately owned rights. References herein to any specific commercial product, process, or service by trade name, trade mark, manufacturer, or otherwise, does not necessarily constitute or imply its endorsement, recommendation, or favoring by the U.S. Government or any agency thereof. The views and opinions of authors expressed herein do not necessarily state or reflect those of the U.S. Government or any agency thereof. 



\section{SUMMARY}

Nuclear fuel reprocessing produces off-gas streams containing several radioactive components that must be captured for further treatment or storage. As part of the Off-Gas Sigma Team, parallel research at INL and PNNL has produced several promising sorbents for the selective capture of xenon and krypton from surrogate off-gas stream compositions. In order to design full-scale treatment systems, sorbents that are promising on a laboratory scale must be tested under process conditions prior to consideration for pilot testing and eventual full-scale application. To that end, a bench-scale multi-column system with capability to test multiple sorbents was designed and constructed at INL. This report details multi-column testing of CaSDB MOF produced at PNNL.

Two multi-column tests were performed with the CaSDB MOF installed in the first column for Xe capture, followed with HZ-PAN installed in the second column for $\mathrm{Kr}$ capture. The Xe column was placed in a Stirling Ultracold cooler while the custom designed cryostat was employed for the Kr column. Test temperatures of $253 \mathrm{~K}$ and $191 \mathrm{~K}$ were selected for the Xe column while the $\mathrm{Kr}$ column was held at $191 \mathrm{~K}$ for both tests. At the conclusion of each test, samples were collected from each column, via calibrated-volume sample bombs, and analyzed for gas composition. Desorption cycles were also performed on individual columns following each test to account for all sorbate species from each column. Analyses of the samples indicated that CaSDB MOF did not have a high selectivity for Xe over $\mathrm{Kr}$ and consequently produced a Xe stream with relatively high $\mathrm{Kr}$ contamination as well as excess $\mathrm{Xe}$ on the $\mathrm{Kr}$ column.

During handling of the CaSDB MOF it was noted that it was highly susceptible to friction damage, shedding dust with light handling. Each time the material was transferred to a column for testing or a container for storage, the friction of gentle handling resulted in a loss of one to three weight percent of the material.

While test results indicate CaSDB MOF appears to have good capacity for Xe, the short time to initial breakthrough would make design of a continuous adsorption/desorption cycle difficult, requiring either very large columns or a large number of smaller columns. Because of the tenacity with which $\mathrm{Xe}$ and $\mathrm{Kr}$ adhere to the material once adsorbed, this CaSDB MOF may be more suitable for use as a long-term storage solution. Further testing is recommended to determine if CaSDB MOF is suitable for this purpose. 


\section{CONTENTS}

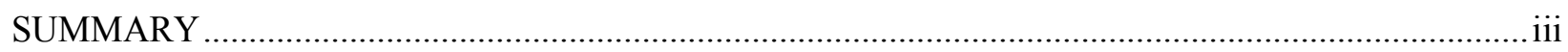

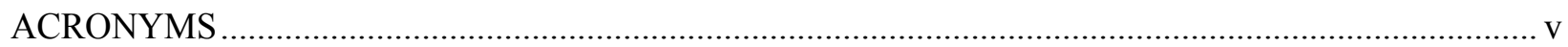

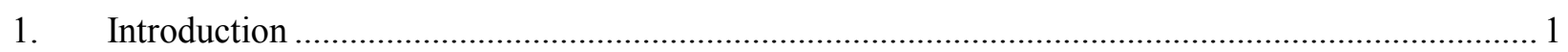

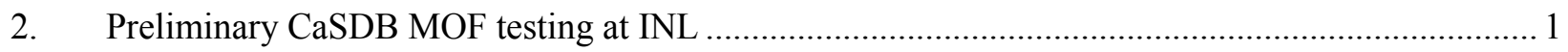

3. Multi-Column CaSDB MOF Test Plan Design ....................................................................... 3

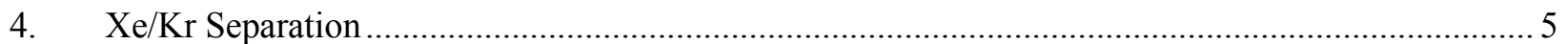

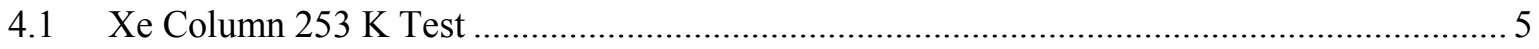

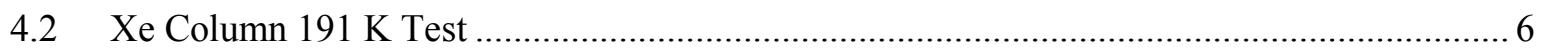

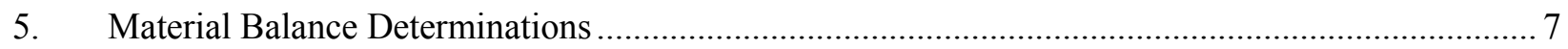

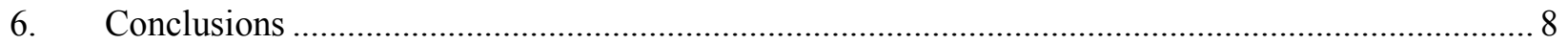

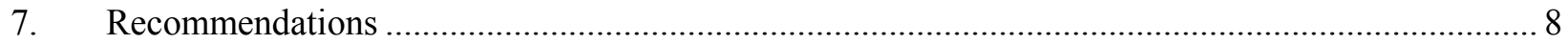

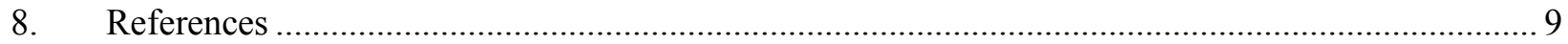

\section{FIGURES}

Figure 1. CaSDB MOF (10.26 g) in a stainless steel column $15.24 \mathrm{~cm}$ x $1.27 \mathrm{~cm}, 50 \mathrm{sccm}$ Air with $150 \mathrm{ppm} \mathrm{Kr}$ and $1000 \mathrm{ppm} \mathrm{Xe}$ at various temperatures............................................. 2

Figure 2. Comparison of krypton initial breakthrough times in He and Air............................................ 4

Figure 3. Initial Kr breakthrough times for HZ-PAN and CaSDB MOF.............................................. 5

\section{TABLES}

Table 1. Results of preliminary testing of CaSDB MOF at INL ....................................................... 2

Table 2. Xe and $\mathrm{Kr}$ breakthrough times normalized to $50 \mathrm{sccm}$ feed gas through 33 grams of

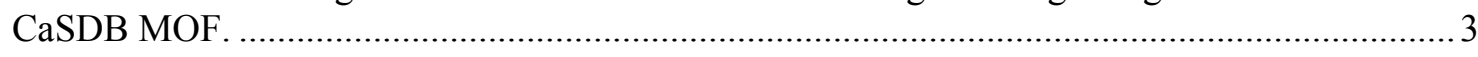

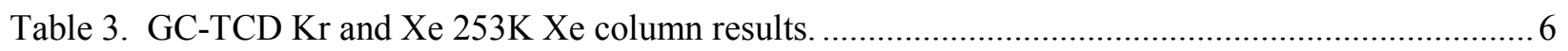

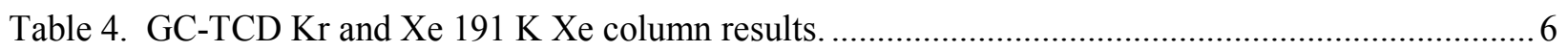

Table 5. Xe and $\mathrm{Kr}$ material balance based upon analytical results........................................................ 7 


\section{ACRONYMS}

AgZ-PAN Silver converted mordenite-polyacrylonitrile

CaSDB calcium-4,4'-sulfonyl dibenzoate

GC-TCD Gas Chromatograph with Thermal Conductivity Detector

HZ-PAN Hydrogen mordenite-polyacrylonitrile

INL Idaho National Laboratory

K Kelvin

MOF Metal-Organic Framework

PNNL Pacific Northwest National Laboratory

PPMV Part per million volume

SCCM Standard Cubic Centimeters per Minute 


\section{MULTI-COLUMN EXPERIMENTAL TEST BED USING CASDB MOF FOR XE/KR SEPARATION}

\section{Introduction}

Research supporting the Off-Gas Sigma Team has focused on capture technologies to mitigate environmental emissions which may result in health concerns stemming from used nuclear fuel reprocessing. Parallel research at Idaho National Laboratory (INL) and Pacific Northwest National Laboratory (PNNL) has resulted in the development of several innovative unique sorbents that can be used effectively to capture and selectively separate krypton $(\mathrm{Kr})$ and xenon $(\mathrm{Xe})$ isotopes. Research at PNNL has focused primarily on metal-organic framework (MOF) sorbents, while research at INL has focused on mordenites in polyacrylonitrile (PAN) matrices in engineered form. As promising new sorbents were developed, the need arose to test them under conditions approaching potential operating conditions. Consequently, a multi-column test bed was designed and built at INL to evaluate physical properties, measure capacities, and the ability of sorbents to selectively separate $\mathrm{Xe}$ from $\mathrm{Kr}$ to determine the purity of $\mathrm{Kr}$ in the final captured stream [1].

Previous research at PNNL demonstrated that a calcium-4, 4'-sulfonyl dibenzoate (CaSDB) MOF engineered form sorbent showed selectivity for $\mathrm{Xe}$ over $\mathrm{Kr}$ at ambient temperature [2]. In order to test the CaSDB MOF on a larger scale and in a multi-column configuration, $\sim 50$ grams was produced at PNNL and shipped to INL for further testing.

\section{Preliminary CaSDB MOF testing at INL}

Upon arrival, the MOF sample was carefully removed from the packing material, weighed, and transferred to a $60 \mathrm{~mL}$ plastic sample bottle. Initial weight of the material was 46.87 grams. It was noted during handling and transfer that a great deal of very fine dust was released requiring a fume hood to contain the material. Prior to any testing, sorbents require activation to remove residual moisture, so the MOF sample was activated under a vacuum of 20-22 inches of $\mathrm{Hg}$ for ten hours at $373 \mathrm{~K}$, in accordance with instructions from PNNL. After activation, the material was weighed again to determine weight loss due to release of entrained moisture. Post activation weight was $44.54 \mathrm{~g}$, indicating a loss of 2.33 grams, or $5.2 \%$, some of which was due to fine dust that remained attached to the walls of the activation column and the remainder due to removal of entrained moisture.

Prior to performing multi-column testing it was necessary to perform preliminary tests to determine the time to initial breakthrough of both $\mathrm{Kr}$ and $\mathrm{Xe}$. The breakthrough tests were run long enough to ensure the breakthrough curves were well-established for both $\mathrm{Kr}$ and $\mathrm{Xe}$, but not long enough to reach full Xe capacity.

Preliminary tests were performed at 295, 253, and $191 \mathrm{~K}$. These tests were conducted in a stainless steel column $15.24 \mathrm{~cm}$ in length and $1.1 \mathrm{~cm}$ internal diameter. The column was filled with 10.56 grams of CaSDB MOF material. A light tap material packing technique was utilized to ensure minimal void space while minimizing damage to the sorbent material. The column was wrapped with heat tape for controlling desorption temperatures. The column was then installed in a Stirling Ultracold cooler used to control the column to selected temperatures during testing. After the first two tests, the MOF sample was removed and stored in a sealed container. The same MOF sample was re-installed in the column for more preliminary testing. At re-install, the material weight was 10.25 grams, a loss of 0.31 grams, or $2.9 \%$ from dusting during handling. MOF weight after completion of all preliminary tests and removal from the column was 9.92 grams. The total loss of 0.65 grams, or $6.0 \%$, was due to dust evolving from the sorbent. 
A total of four tests were performed in order to determine runtimes and temperatures for multi-column testing. Table 1 details test conditions and results. These initial breakthrough times for $\mathrm{Kr}$ and $\mathrm{Xe}$ were used to define run times as well as temperatures for the multi-column testing.

Table 1. Results of preliminary testing of CaSDB MOF at INL

\begin{tabular}{|c|c|c|c|c|c|c|}
\hline Flow & Temp & \multicolumn{3}{|c|}{ Feed Gas (ppmv) } & \multicolumn{2}{c|}{$\begin{array}{c}\text { Breakthrough time } \\
\text { (min) }\end{array}$} \\
$3 / \mathrm{min})$ & $(\mathrm{K})$ & $\mathrm{Kr}$ & $\mathrm{Xe}$ & Balance & $\mathrm{Kr}$ & $\mathrm{Xe}$ \\
\hline \hline 20 & 295 & 150 & 1000 & Air & 6 & 26.4 \\
\hline 20 & 253 & 150 & 1000 & Air & 10.2 & 143 \\
\hline 20 & 191 & 150 & 1000 & Air & 9.6 & 247 \\
\hline 20 & 191 & 2544 & 0 & He & 30 & $\mathrm{n} / \mathrm{a}$ \\
\hline
\end{tabular}

Cycle effect testing had not been reported for CaSDB MOF previously so it was unknown prior to testing whether there was a possibility the MOF would lose capacity or selectivity for Xe over $\mathrm{Kr}$ after several thermal swing cycles. In order to ensure multi-column testing was performed with material in pristine condition, preliminary testing was conducted on a smaller sample, reserving the bulk of the MOF material for the essential tests. The test flow rate for multi-column testing was predetermined to be the same as that used for previous testing of INL materials. In order to allow preliminary testing of a small quantity of MOF material while keeping the tests analogous to later multi-column tests, the test flow rate for preliminary testing was calculated to maintain the same flow regime, identical Reynold's number and channel velocity, as would be seen during multi-column tests. The Xe and Kr breakthrough curves obtained from these preliminary tests can be seen in Figure 1.

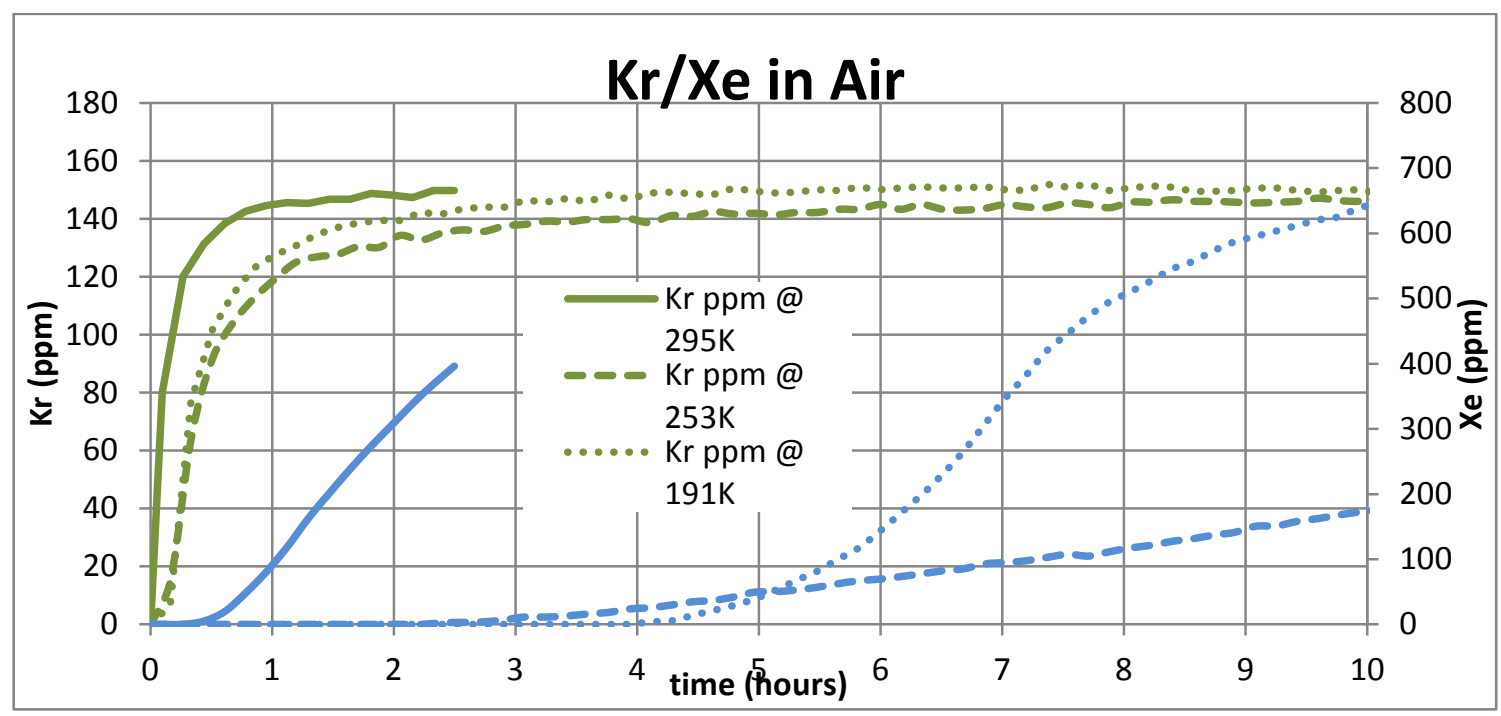

Figure 1. CaSDB MOF (10.26 g) in a stainless steel column $15.24 \mathrm{~cm}$ x $1.27 \mathrm{~cm}, 50 \mathrm{sccm}$ Air with $150 \mathrm{ppm} \mathrm{Kr}$ and $1000 \mathrm{ppm} \mathrm{Xe}$ at various temperatures. 
Of particular interest was the fact that initial Xe breakthrough at $295 \mathrm{~K}$ occurred prior to $\mathrm{Kr}$ reaching complete breakthrough. This presented one of three possibilities for the multi-column tests: 1) relatively high $\mathrm{Kr}$ concentration on the Xe-capture sorbent, with the consequential $\mathrm{Kr}$ contamination of the $\mathrm{Xe}$ stream from desorption, 2) relatively high concentration of $\mathrm{Xe}$ on the $\mathrm{Kr}$-capture sorbent, reducing $\mathrm{Kr}$ purity and requiring either further separation or larger $\mathrm{Kr} / \mathrm{Xe}$ long-term storage capacity, 3) reduced purity of both $\mathrm{Kr}$ and $\mathrm{Xe}$ after the adsorption/desorption cycle. These results necessitated some deviation from the initial test plan.

\section{Multi-Column CaSDB MOF Test Plan Design}

The proposed test plan for the associated milestone was to perform two multi-column tests using CaSDB MOF in the same manner as those used for AgZ-PAN and HZ-PAN during FY15 [1]. However, after reviewing the preliminary testing results and consulting with Sigma Team members, the plan was modified to account for differences in physical and selectivity characteristics between CaSDB MOF and AgZ-PAN.

CaSDB MOF is nearly twice as dense as AgZ-PAN. Placing only $18 \mathrm{~g}$ of the material in the $22.9 \times 1.9 \mathrm{~cm}$ column would have resulted in the column being approximately half full. Additionally, as seen in Figure 1, time to initial breakthrough for Xe was relatively short. In order to maximize testing time and ensure a $\mathrm{Xe}$-free $\mathrm{Kr}$ gas was introduced to the $\mathrm{Kr}$ column, the decision was made to fill the Xe-capture column to capacity with CaSDB MOF, a total of $33.80 \mathrm{~g}$.

The multi-column test setup at INL uses a gas chromatograph with a thermal conductivity detector (GC$\mathrm{TCD}$ ) to monitor gas composition exiting the first column to ensure detectible Xe does not enter the second $\mathrm{Kr}$-capture column. Time between analyses is approximately 11 minutes. The lag between gas analysis requires a conservative approach when determining appropriate test times. Thus multi-column test time is determined by cutting time to initial Xe breakthroughs by a factor of two to ensure as little Xe as possible enters the $\mathrm{Kr}$-capture column. To estimate time to initial breakthrough of Xe from preliminary testing, the observed times to initial breakthrough (Table 1) were normalized to $50 \mathrm{sccm}$ feed gas through 33 grams of CaSDB MOF (Table 2).

Table 2. Xe and Kr breakthrough times normalized to $50 \mathrm{sccm}$ feed gas through 33 grams of CaSDB MOF.

\begin{tabular}{cccccccc} 
Temp & \multicolumn{2}{c}{ Feed Gas (ppmv) } & \multicolumn{2}{c}{$\begin{array}{c}\text { Normalized } \\
\text { Breakthrough Time (min) }\end{array}$} & $\begin{array}{c}\text { Testing } \\
\text { Time } \\
(\text { min) }\end{array}$ & $\begin{array}{c}\text { \# of } \\
\text { Analyses }\end{array}$ \\
\hline \hline 295 & 150 & 1000 & Air & 7.5 & 33 & 16 & $\mathbf{1}$ \\
253 & 150 & 1000 & Air & 12.8 & 179 & 90 & $\mathbf{8}$ \\
191 & 150 & 1000 & Air & 12.3 & 309 & 150 & $\mathbf{1 4}$ \\
\hline \hline
\end{tabular}

Examination of normalized breakthrough times showed that a test at $295 \mathrm{~K}$ would provide only one analytical data point, allowing insufficient time for the feed gas to fill the void volume in the cryostat, and would therefore be of no value. Tests at $253 \mathrm{~K}$ and $191 \mathrm{~K}$, however, would provide sufficient analytical data points. Hence, $253 \mathrm{~K}$ and $191 \mathrm{~K}$ were selected as the temperatures for the Xe column for the multicolumn tests. 
Multi-column testing is designed to minimize select sorbate losses for both columns. Therefore, tests must also be stopped prior to initial $\mathrm{Kr}$ breakthrough from the second column. Scrutiny of initial breakthrough times for $\mathrm{Kr}$ (Figure 2) revealed a low selectivity for $\mathrm{Kr}$ and a very short time to initial $\mathrm{Kr}$ breakthrough even in the absence of Xe (Figure 2 red series). This best-case scenario indicates approximately 30 minutes to initial $\mathrm{Kr}$ breakthrough, allowing only 15 minutes of multi-column run time. Since the GC-TCD analyzes the gas every 11 minutes and the test duration would be limited to 15 minutes, CaSDB MOF is not suitable for use in the $\mathrm{Kr}$ column under these conditions.

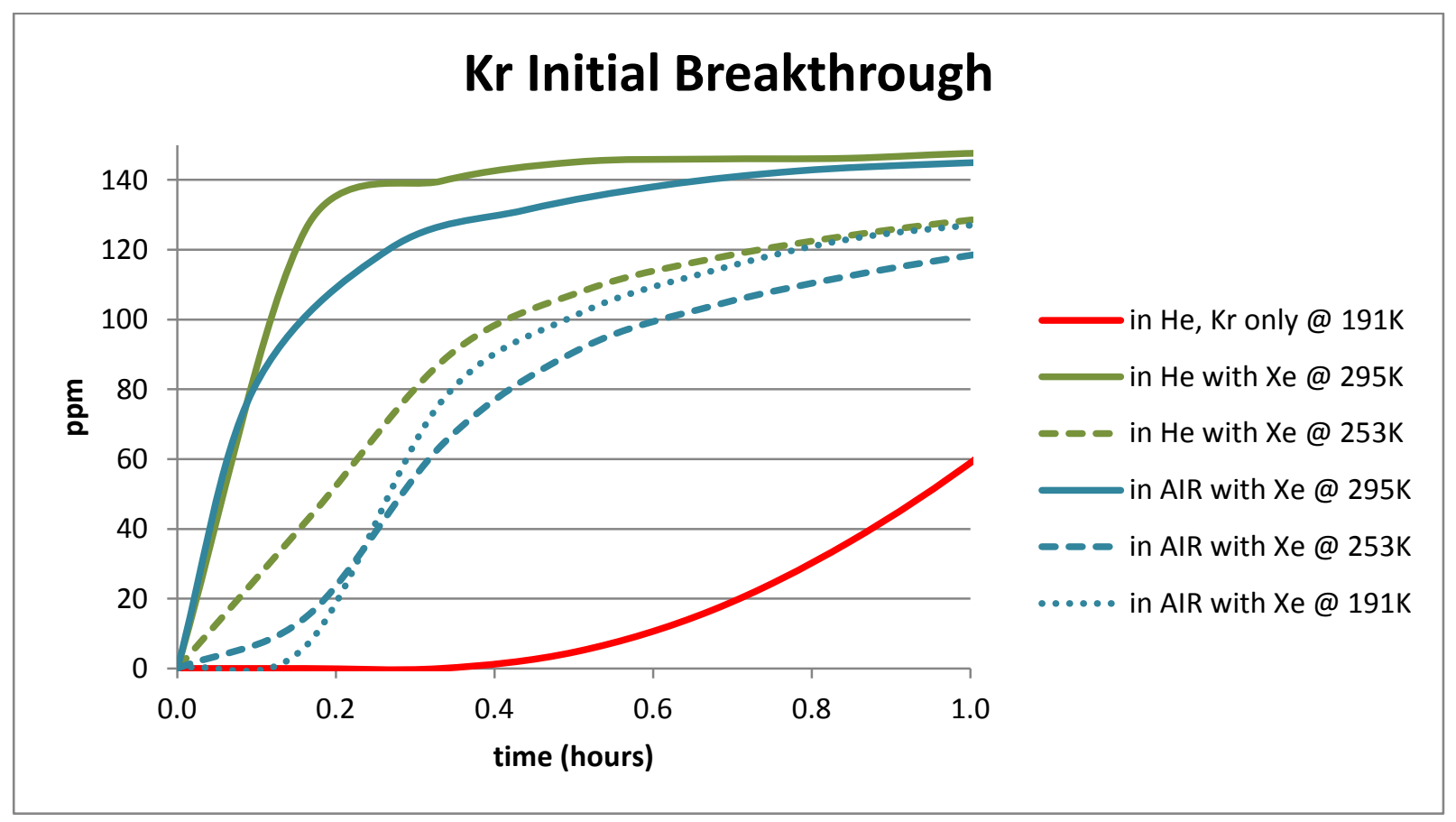

Figure 2. Comparison of krypton initial breakthrough times in He and Air.

By comparison, HZ-PAN under similar test conditions took nearly seven hours to reach initial $\mathrm{Kr}$ breakthrough at $191 \mathrm{~K}$ (Figure 3). The decision was made, with input from sigma team leads, to use HZPAN as the sorbent in the Kr column. Using HZ-PAN in the Kr column allowed adequate time to test the ability of CaSDB MOF to separate Xe from $\mathrm{Kr}$ while still preventing $\mathrm{Kr}$ from escaping the system the decision was made, with input from sigma team leads, to use HZ-PAN as the sorbent in the $\mathrm{Kr}$ column. 


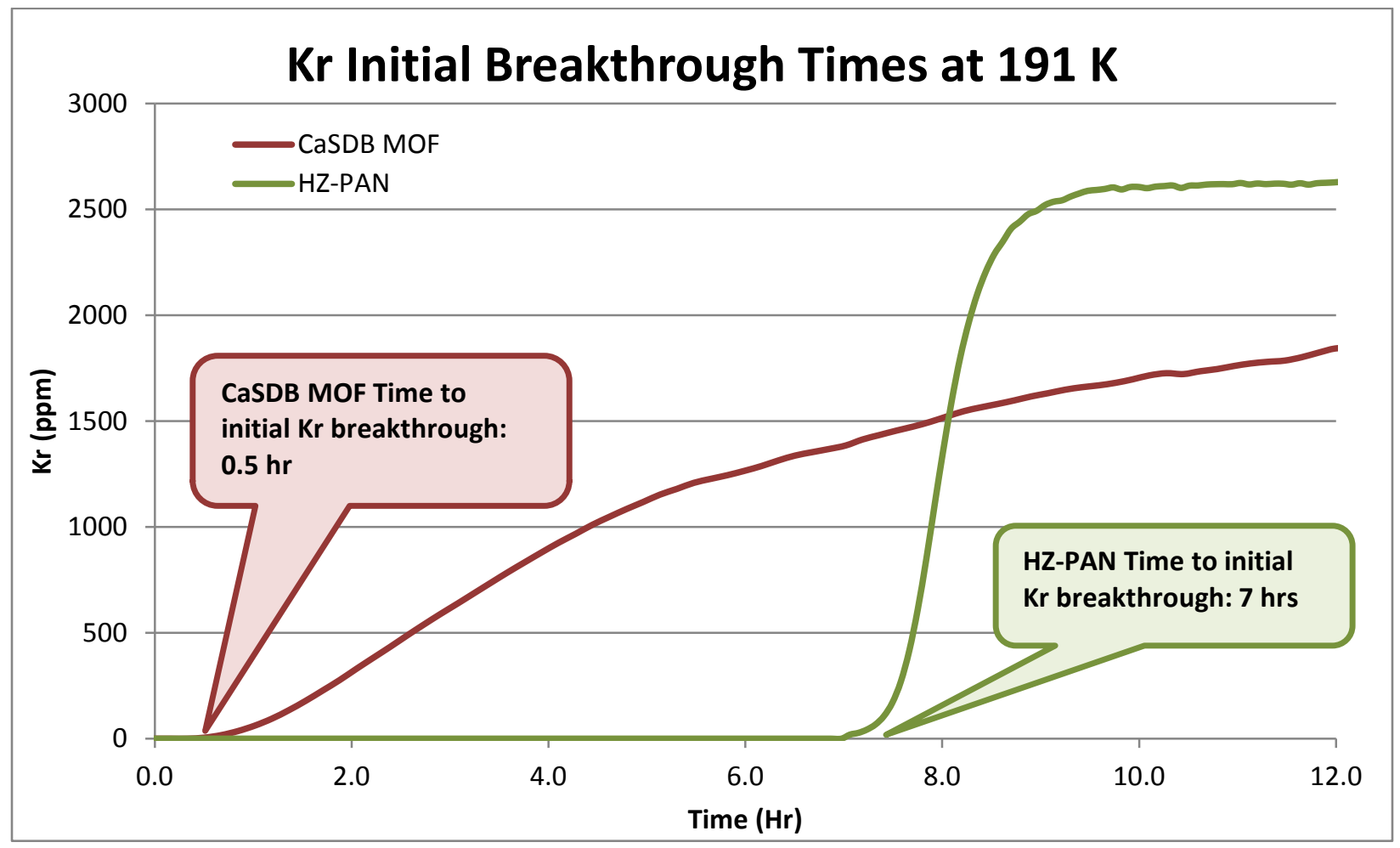

Figure 3. Initial Kr breakthrough times for HZ-PAN and CaSDB MOF.

\section{4. $\mathrm{Xe} / \mathrm{Kr}$ Separation}

In order to demonstrate the separation of Xe from $\mathrm{Kr}$ utilizing the multi-column test system, two adsorption tests were performed using a feed gas of $1000 \mathrm{ppmv} \mathrm{Xe}, 150 \mathrm{ppmv} \mathrm{Kr}$ with a balance of air flowing at $50 \mathrm{sccm}$. The Xe column contained 33.80 grams of CaSDB MOF and temperature was maintained at $253 \mathrm{~K}$ and $191 \mathrm{~K}$ for the two tests, respectively. The gas exiting this column was then routed through the GC-TCD to monitor for $\mathrm{Xe}$ and $\mathrm{Kr}$ and subsequently sent to the cryostat for $\mathrm{Kr}$ capture. The cryostat $\mathrm{Kr}$ column contained 4.45 grams of HZ-PAN sorbent and temperature was maintained at $191 \mathrm{~K}$ for both tests. The gas exiting the cryostat was vented to atmosphere and was not analyzed. Samples of each column were taken utilizing evacuated sample bombs and were analyzed for Xe and $\mathrm{Kr}$ via GCTCD.

\subsection{Xe Column $253 \mathrm{~K}$ Test}

The first test was performed with the multi-column system by maintaining the Xe column at $253 \mathrm{~K}$ and the $\mathrm{Kr}$ column at $191 \mathrm{~K}$. Preliminary tests at $253 \mathrm{~K}$ showed that Xe should not start to break through the CaSDB MOF for nearly three hours of feed gas flow. Based on this information, a conservative test time of $\sim 88$ minutes, corresponding to eight analysis points from the GC-TCD, was chosen to minimize the amount of Xe that would end up on the Kr column. After the eighth injection to the GC, both columns were isolated and all lines were purged with helium. During the test, it was noted that Xe breakthrough in low concentrations occurred at the first GC injection and continued throughout the test, climbing slowly but steadily to $93 \mathrm{ppm}$ by the time the test was complete. Ideally, no Xe would have been detected for the duration of the test, but it was decided to allow the test to run long enough to obtain eight analysis points.

To obtain a sample of the Xe column, the heater was turned on to a set point of $373 \mathrm{~K}$, and a $500 \mathrm{~mL}$ sample bomb evacuated to -19 inches of $\mathrm{Hg}$ was connected to sample port. A leak check was conducted. 
No leaks were present so the sample valve was opened. As the column temperature rose, the vacuum on the sample bomb decreased to -6 inches of Hg. After three hours, the sample valve was closed and the sample bomb was removed from the system. To obtain a sample of the $\mathrm{Kr}$ column, the cryostat temperature controller was set to $400 \mathrm{~K}$, which correlates to $370 \mathrm{~K}$ at the center of the $\mathrm{Kr}$ column, and a 6 liter sample bomb evacuated to 13 inches of $\mathrm{Hg}$ was connected to the $\mathrm{Kr}$ column and the sample valve was opened. As the cryostat temperature reached $370 \mathrm{~K}$, the vacuum on the sample bomb decreased to zero inches of $\mathrm{Hg}$. After three hours the sample valve was closed and the sample bomb was removed from the system. The results of the GC-TCD analyses of these samples are reported in Table 3.

Table 3. GC-TCD Kr and Xe 253K Xe column results.

\begin{tabular}{ccc} 
Column Sample & Average Xe (ppm) & Average Kr (ppm) \\
\hline \hline Xe Column & 204 & 57.5 \\
Kr Column & ND $^{*}$ & 22.7 \\
\hline \hline
\end{tabular}

${ }^{*}$ Non-detect

\subsection{Xe Column $191 \mathrm{~K}$ Test}

A second separation test was performed with the multi-column system by maintaining both the Xe column and the Kr column at $191 \mathrm{~K}$. Preliminary tests at $191 \mathrm{~K}$ showed that Xe should not start to break through the CaSDB MOF until five hours of feed gas flow at $50 \mathrm{sccm} . \mathrm{Kr}$ at $191 \mathrm{~K}$ with this feed gas and HZ-PAN sorbent mass may begin to breakthrough after two hours of feed gas flow. Based on this information, a conservative test time of 105 minutes was chosen to prevent $\mathrm{Kr}$ loss from the $\mathrm{Kr}$ column. After 105 minutes of feed gas flow, both columns were isolated.

A $500 \mathrm{~mL}$ sample bomb evacuated to -22 inches of $\mathrm{Hg}$ was connected to the Xe column and opened immediately. The column heater was set at $373 \mathrm{~K}$. A $6 \mathrm{~L}$ sample bomb evacuated to -12 inches of $\mathrm{Hg}$ was connected to the $\mathrm{Kr}$ column and opened immediately. The cryostat heater temperature set point was set to $420 \mathrm{~K}$, the set point that would result in a temperature of $373 \mathrm{~K}$ in the center of the column. Both columns were allowed to remain at $373 \mathrm{~K}$ overnight to determine whether additional time would allow $\mathrm{Kr}$ and $\mathrm{Xe}$ to release from the CaSDB without helium flow. When the sample valves were closed and the sample bombs removed from the system, the Xe-capture sample bomb pressure had increased to -6 inches $\mathrm{Hg}$ and the $\mathrm{Kr}$-capture sample bomb pressure had increased to 0 inches $\mathrm{Hg}$. Analyses for both $\mathrm{Xe}$ and $\mathrm{Kr}$ were performed on an Agilent GC-TCD analyzer on both the Xe column and the Kr column samples. The GCTCD results from this test are presented in Table 4.

Table 4. GC-TCD Kr and Xe $191 \mathrm{~K}$ Xe column results.

\begin{tabular}{ccc} 
Column Sample & Average Xe (ppm) & Average Kr (ppm) \\
\hline \hline Xe Column & 65.9 & 135 \\
Kr Column & ND $^{*}$ & 23.2 \\
\hline \hline
\end{tabular}

\footnotetext{
${ }^{*}$ Non-detect
} 


\section{Material Balance Determinations}

Complete material balances for the multi-column system provide insight and validation for the overarching purpose of separating Xe from $\mathrm{Kr}$ in a mixed gas feed. Samples of both the Xe column and the $\mathrm{Kr}$ column were obtained using sample bombs under desorption conditions. Additionally, column effluent gases were monitored using GC-TCD during desorption in order to determine how much of each adsorbed species was present in each column after completion of the adsorption tests.

It was noted during preliminary testing that desorption of $\mathrm{Kr}$ and $\mathrm{Xe}$ from $\mathrm{CaSDB}$ required helium flow and elevated temperature for a longer than expected period of time. In conjunction with sample bomb results from multi-column testing in FY15 [1], it was expected that only a potentially undetectable portion of the $\mathrm{Kr}$ and $\mathrm{Xe}$ that adsorbed onto the columns would end up in the sample bombs for analyses.

In an attempt to account for all of the $\mathrm{Kr}$ and $\mathrm{Xe}$ adsorbed during the multi-column test, desorption cycles were used to determine the moles of sorbate remaining on each column separately. For desorption cycles, helium flow was established at $50 \mathrm{sccm}$ through each column separately at $370 \mathrm{~K}$. Effluent was analyzed using GC-TCD to determine how much $\mathrm{Kr}$ and Xe remained on the column after sampling. The GC analysis from desorption confirmed that the majority of the $\mathrm{Kr}$ and $\mathrm{Xe}$ gases remained on the sorbents after gas bomb sampling. Desorption results are tabulated below (Table 5).

Table 5. Xe and Kr material balance based upon analytical results.

\begin{tabular}{|c|c|c|c|c|}
\hline & \multicolumn{2}{|c|}{ 253K Test } & \multicolumn{2}{|c|}{ 191K Test } \\
\hline & $\mathrm{Xe}(\mathrm{mol})$ & $\mathrm{Kr}(\mathrm{mol})$ & $\mathrm{Xe}(\mathrm{mol})$ & $\mathrm{Kr}(\mathrm{mol})$ \\
\hline Total processed & $1.68 \mathrm{E}-04$ & $2.55 \mathrm{E}-05$ & $2.09 \mathrm{E}-04$ & $3.18 \mathrm{E}-05$ \\
\hline Adsorbed on Xe column ${ }^{1}$ & $1.64 \mathrm{E}-04$ & $6.16 \mathrm{E}-06$ & $2.08 \mathrm{E}-04$ & $6.21 \mathrm{E}-06$ \\
\hline Desorbed from Xe column ${ }^{2}$ & $1.56 \mathrm{E}-04$ & $4.08 \mathrm{E}-06$ & $2.05 \mathrm{E}-04$ & $3.01 \mathrm{E}-05$ \\
\hline Feed to $\mathrm{Kr}$ column ${ }^{2}$ & 4.37E-06 & $1.94 \mathrm{E}-05$ & $1.07 \mathrm{E}-06$ & $2.56 \mathrm{E}-05$ \\
\hline Desorbed from $\mathrm{Kr}$ column ${ }^{2}$ & $1.86 \mathrm{E}-06$ & $1.52 \mathrm{E}-06$ & 4.99E-06 & $2.01 \mathrm{E}-06$ \\
\hline In sample bombs ${ }^{3}$ & 8.43E-09 & 3.31E-09 & $5.58 \mathrm{E}-09$ & $3.68 \mathrm{E}-09$ \\
\hline Total Accounted For & $1.58 \mathrm{E}-04$ & $5.60 \mathrm{E}-06$ & $2.10 \mathrm{E}-04$ & $3.21 \mathrm{E}-05$ \\
\hline Final Material Balance $^{4}$ & $94 \%$ & $22 \%$ & $101 \%$ & $101 \%$ \\
\hline
\end{tabular}

The material balance falls within instrument error, validating analytical results, for all but $\mathrm{Kr}$ for the $253 \mathrm{~K}$ test. In that case, the error is attributed to timing of helium flow to the cryostat during desorption in relation to the 11 minute lag between GC-TCD analyses. $\mathrm{Kr}$ is difficult to capture with the GC as it desorbs very rapidly from HZ-PAN, the majority desorbing within the first 2-3 minutes. Consequently, the 11-minute lag between analyses introduces significant error. The optimum time to start desorption gas flow is two minutes before the next GC-TCD sample. However, during the desorption cycle for the $253 \mathrm{~K}$ 
test helium flow was started six minutes before the GC-TCD sample, allowing the majority of the Kr to be released prior to being analyzed.

\section{Conclusions}

Although the performance of the CaSDB MOF looked very promising under reported test conditions, on a larger scale, Xe breakthrough happened very quickly with respect to the amount of sorbent present in the system and the feed gas flow. This is of concern as it would require a much larger quantity of sorbent material to accomplish adequate $\mathrm{Xe} / \mathrm{Kr}$ selective separation, or rapid thermal swing cycling. Coupled with the tenacity with which CaSDB MOF holds Xe and $\mathrm{Kr}$, operations would be difficult to control. However, this testing was designed to be as similar as possible to previous testing of the combination of AgZ-PAN and HZ-PAN and was not a comprehensive series of tests to determine the best possible conditions for this material. There may be other test conditions that would better capture the capabilities of this MOF material.

Preliminary test results suggest that despite a reasonable capacity for $\mathrm{Kr}$, CaSDB MOF does not exhibit sufficiently rapid $\mathrm{Kr}$ capture kinetics. While reducing temperature to cryogenic conditions does extend the period of time before initial $\mathrm{Kr}$ breakthrough, even at $191 \mathrm{~K} \mathrm{Kr}$ breakthrough happened quickly. For this reason, it was not used in the Kr-capture column in the cryostat and HZ-PAN was used for that purpose. However, the MOF material does appear to have good capacity for $\mathrm{Kr}$ and a tendency to retain $\mathrm{Kr}$ once captured. Provided $\mathrm{Kr}$ could be separated sufficiently from nitrogen, preliminary observations suggest CaSDB MOF could be promising as part of a capture and store scenario in a pressure vessel.

During desorption, it was observed that $\mathrm{Xe}$ and $\mathrm{Kr}$ adhere more strongly to the CaSDB MOF than previously tested mordenite materials. Extended desorption times and continuous helium flow were required to remove all of the $\mathrm{Kr}$ and $\mathrm{Xe}$ from the material. This could be problematic for cyclical operation. However, the microstructure of the MOF may be robust enough to tolerate higher temperatures during desorption, which would likely decrease the required regeneration time. Optimum desorption conditions were not explored as part of this testing, but would be worthwhile for future testing.

Along with $\mathrm{Kr}$ and $\mathrm{Xe}$, CaSDB MOF also adsorbed a large amount of nitrogen and showed a high affinity for water. Even short exposures to ambient air resulted in the need to reactivate the material to eliminate the water peak on the GC analysis. Nitrogen adsorption is likely due to the overwhelming amount of nitrogen present in air compared to $\mathrm{Kr}$ and $\mathrm{Xe}$. Although this testing was not focused on nitrogen, it does not appear that the sorbent is particularly selective for nitrogen.

The primary area of potential concern with the MOF material was its tendency to break down and emit fine dust with even very gentle handling or during normal operation in a slow, fully laminar flow gas stream running through the packed bed. This could present handling and operations issues in a full-scale facility. A more mechanically stable engineered form may solve this issue. However, it must be noted that dusting of this magnitude has not been observed during testing at PNNL [2]. It is unknown whether the dusting observed during INL testing is inherent to the material itself and became apparent with increased material quantity, or if it is a byproduct of changes in the material production process necessitated by the need for much larger quantities required for multi-column testing.

\section{Recommendations}

Further investigation of appropriate adsorption/desorption conditions for the material should be investigated to determine the best possible parameters for CaSDB MOF. More complete characterization of material properties may reveal test parameters that more successfully highlight the strengths of this MOF. 
Future multi-column testing of MOF materials may more fully capture their capabilities if two different materials are used, one for Xe capture and one for Kr capture. Alternately, if one MOF displays characteristics appropriate for both $\mathrm{Kr}$ and Xe capture, a multi-column test could be designed using temperature and flow conditions that would be the most advantageous for the material in question.

Current MOF materials present difficulties for handling and mechanical stability. Further investigation into alternate engineered forms for MOF materials is warranted.

The stronger bonding characteristics observed during desorption cycles suggests further testing for waste form storage utilization may be warranted.

Continued testing of sorbents in INL's multi-column system to ensure uniformity of testing and avoid duplication of work and extraneous equipment expenditure is suggested. For future testing, a sampling protocol more capable of determining $\mathrm{Kr}$ and $\mathrm{Xe}$ purity from desorption should be developed, particularly for sorbents that require gas flow, in addition to elevated temperatures, to desorb $\mathrm{Kr}$ and $\mathrm{Xe}$.

Material properties that present no concerns in very small quantities can cause some difficulties on a larger scale. Although criteria for full-scale sorbents are currently being defined by the Sigma team, they have not yet been fully established. Criteria for scale-up testing should also be established. Future materials should be fully characterized with respect to physical and chemical properties, isotherms, capacities and selectivities, as well as meet minimum handling criteria prior to being submitted for testing on a larger scale.

The use of sample bombs to analyze sorbate captured on the columns proved to be less than satisfactory as was experienced in FY 15 testing. Material balance calculations from desorption analyses provided a more accurate picture of the fate of the sorbates during multi-column testing. The use of sample bombs to obtain sorbate compositions should be eliminated in favor of desorption strategies to close material balances for future multi-column tests.

\section{References}

1. Garn, T.G., Greenhalgh, M., Law, J.D., "Multi-Column Experimental Test Bed for Xe/Kr Separation”, FCRD-MRWFD-2015-000047, August 30, 2015.

2. Personal Communications, Praveen Thallapally. August, 2015. 